\title{
Language and Reading through Drama: Teachers' Self-Efficacy
}

\author{
Amanda Melville, Lama Farran \\ Department of Counseling, Higher Education, and Speech-Language Pathology, University of West Georgia, Georgia, USA \\ Email: amelvil1@my.westga.edu
}

How to cite this paper: Melville, A., \& Farran, L. (2021). Language and Reading through Drama: Teachers' Self-Efficacy. Open Journal of Modern Linguistics, 11, 703-709. https://doi.org/10.4236/ojml.2021.114055

Received: July 7, 2021

Accepted: August 28, 2021

Published: August 31, 2021

Copyright (c) 2021 by author(s) and Scientific Research Publishing Inc. This work is licensed under the Creative Commons Attribution International License (CC BY 4.0).

http://creativecommons.org/licenses/by/4.0/

\begin{abstract}
This pilot study examined the effect of drama exposure on preservice teachers' self-efficacy beliefs regarding the language and reading development of their preschool students. Preservice teachers completed a survey before and after they participated in drama workshops. Results revealed statistically significant differences in pre- to post-ratings of teacher self-efficacy beliefs and attitudes regarding teaching language and reading skills, pointing to the potential impact of drama integration on teacher beliefs, which likely shape future instructional practices.
\end{abstract}

\section{Keywords}

Drama, Language, Reading, Preschool Children, Preservice Teachers

\section{Introduction}

Recent research reinforces the power of infusing the arts to engage students in every part of their learning (Bodrova \& Leong, 1996; Diamond \& Lee, 2011; Riggs et al., 2006). Evidence from the neuroscience of learning shows that the arts promote children's symbolic representations, conceptual thought, and innovation and has been associated with a remarkable increase in sustained attention during artsrelated activities and beyond (Posner et al., 2008, Wandell et al., 2008). As such, drama integration is thought to be conducive to student engagement as it fosters children's active participation in authentic learning experiences and affords them numerous avenues for self-expression (Anderson et al., 2019; Cawthon, Dawson, \& Ihom, 2011; Saraniero, Goldberg, \& Hall, 2014).

Specifically, drama plays a crucial role in helping children better understand and use language. Through sociodramatic play, children are invited to create new worlds, assume various roles, and act out diverse scenarios through multiple mod- 
es of expression, including sharing stories and using symbols that are representative of their experiences. Consequently, children are encouraged to step out of themselves, think outside the box, and use elaborate, multiple meanings of words that call upon an expansive, rich vocabulary (Alber \& Foil, 2003). The benefit of drama is not confined to language, however, but extends to impact the development of reading (Rieg \& Paquette, 2009; Sun, 2003). Drama is a highly engaging way of creating and re-creating meaningful experiences that reinforce children's understanding and the communicative (oral and gestural) value of written text.

As Mages (2006) proposes, drama embodies the ideal context for language and reading development, positing that drama, language, and reading are causally associated. Furthermore, emerging research related to pedagogy suggests that preservice teachers often resort to drama to enhance children's language and reading development (Huss et al., 2011). Notably, educators from various backgrounds concur that drama-focused professional development programs likely engender new ways of teaching and learning because they promote children's positive development across domains including language (Golinkoff et al., 2006; Huss et al., 2011), executive functions (Diamond et al., 2007; Bodrova \& Leong, 1996), and reading (Rieg \& Paquette, 2009; Sun, 2003). Furthermore, there is evidence suggesting that teachers' perceptions and attitudes about their knowledge and ability to teach a particular domain (e.g., drama) may impact their instructional practices, which then directly affect young children's developmental outcomes. Therefore, examining the beliefs and attitudes of student teachers is paramount as it likely serves as an index of their actual classroom practices.

Even though there is emerging research evidence supporting the benefits of drama, our knowledge about preservice teachers' perceptions and attitudes regarding the use of drama flexibly to serve various functions (e.g., language, self-regulation, and social skills instruction), remains limited. It is thus necessary to test preservice teachers' perceptions about infusing drama in their pedagogy, as these perceptions form the basis for their behaviors, which might directly impede or promote children's positive developmental outcomes. We also believe it would be insightful to obtain similar reports from other caregivers (i.e., parents) pertaining to drama exposure to further corroborate teacher report. This study addresses this gap in research by examining preservice teachers' self-efficacy beliefs and attitudes regarding drama integration in their classroom instruction as well as associations between teacher and parent report.

\section{Theoretical Framework}

This study is grounded in the developmental theories of Bandura (1997) and Vygotsky (1978). Bandura conceptualizes teacher self-efficacy as the teachers' belief of their capacity to accomplish behaviors that result in a specific performance at a specific level. It is associated with teachers' sense of power to engage in certain actions to achieve certain goals, which then determine how teachers behave, feel, reason, and motivate themselves (Bandura, 1997). 
Teachers who do not possess basic knowledge in certain domains, are likely to feel unsuitable for teaching the expected skills, thus demonstrating reduced competence to solve the problems they encounter due to their lack of confidence in their abilities and their perceived task difficulty. Consequently, they tend to try less and show lack of perseverance at the problems they face at school related to the curriculum. As such, the ways in which teachers think about their abilities and perceive their challenges likely influence how they approach their teaching. It is teachers' self-efficacy and confidence, coupled with teachers' development of drama strategies and skills that will determine the extent to which teachers will implement drama in their classroom teaching.

In addition to self-efficacy, the context in which teaching occurs also impacts student learning. Vygotsky (1978) posits that drama is an ideal context for promoting language and cognition based on the conceptualization that drama serves as a means of developing general representational abilities, which ultimately transfer to other domains of functioning including oral and written language development in the early years.

\section{Purpose}

This pilot study explores preservice teachers' beliefs and attitudes toward integrating drama in the curriculum as a function of their exposure to drama workshops delivered in their classrooms as part of their professional development. It also seeks to examine the extent to which teacher report and parent report are associated regarding the effect of drama exposure on language and reading.

\section{Research Questions}

Is there a difference in preservice teachers' self-efficacy beliefs and attitudes about teaching domains of language and reading as a function of their drama experience?

Is there a significant relationship between teacher report and parent report regarding the potential effect of drama experience on children's language and reading skills?

\section{Method}

The participants consisted of 32 preservice teachers ( 29 females and 3 males) who were enrolled in a university-based early childhood education program in the United States of America. Preservice teachers participated in four drama workshops (two workshops per semester) delivered by teaching artists at a local theatre over a period of one academic year and focused on teaching drama strategies. During the last semester of their teacher preparation program, these teachers volunteered to implement drama strategies in their respective early childhood education practicum sites. At the beginning and end of the school year, participants were asked to complete the Drama-Infused Pre-service Teacher Experience Survey (pre- and post-test), which consists of 16 Likertscale items that measure preservice teachers' attitudes and beliefs about using drama in their teaching and 
the extent to which preservice teachers agreed with the benefits of using drama in their teaching ( 1 = Strongly Disagree, $2=$ Disagree, 3 = Agree, $4=$ Strongly Agree) . See Appendix for sample survey items. To minimize survey biases such as central tendency, acquiescence, and social desirability, all survey items were short, six items had negative statements and included indirect questions, and one item was unrelated to drama.

In addition, study participants included 59 parents of preschool children who completed the Drama Experience survey at the beginning and end of the second (last) semester of teacher training, which consists of parallel items to those provided for the teachers. Parents attended two drama experience workshops at the preschool during the last semester of the study, in which teaching artists from a local arts center modeled how to use drama strategies and infuse them in language and reading. Teaching artists also supported parents in their learning and scaffolded their implementation of drama strategies by demonstrating how to take turns during role play, using of props, representing story characters, asking guiding questions, and imagining different settings through using multiple modalities. At the conclusion of the second workshop, parents were requested to complete a paper survey related to their experience, asking them to rate Likertscale survey items based upon how much they thought drama is beneficial and must be infused in teaching language and reading inpreschool.

\section{Data Analysis}

We used a paired samples t-test to examine related groups differences as we were interested in whether the mean of the dependent variable (s) (e.g., language, reading, classroom management) are the same in the groups of preservice teachers when measured at two different time points, before and after participating in the drama workshops.

We were also interested in examining whether there was a significant relationship between teacher and parent report of the preschool children's language and reading before and after teachers and parents participated in the drama workshops. We thus conducted a Kendall's tau-b correlation to test this association.

\section{Results}

A paired samples t-test was conducted in SPSS version 27 to examine the difference in preservice teachers' ratings of survey items, measured before and after the drama workshop experience. There was a statistically significant difference in rating of teachers' perceived ability to teach language skills from the pre-test compared to the post-test $(M=-0.355, S D=0.798), t(30)=-1.36, p=0.01$. Similarly, results indicated a statistically significant difference in rating of teachers' perceived ability to teach reading skills from pre-test compared to post-test ( $M=$ $-0.219, S D=0.608), t(31)=-2.03, p=0.05$.

We also conducted a Kendall's tau-b correlation to measure the strength and direction of the association that exists between teacher report and parent report 
regarding their agreement with respect to infusing drama to teach language and reading skills. There was a strong, positive correlation between teacher report and parent report in the extent to which they agreed on the use of drama to teach language $(r b=0.39, p=0.013)$ and reading $(r b=0.35, p=0.046)$ during the preschool period.

\section{Discussion}

This study sought to examine preservice teachers' self-efficacy beliefs and attitudes regarding drama integration in their teaching. The results demonstrate statistically significant differences in these teachers' perceived abilities to teach language and reading skills before and after participating in drama workshops in their classrooms. Accordingly, drama integration seems to impact various domains, with a positive effect on teaching language and reading skills. This finding is well substantiated in the emerging research on drama (Bodrova \& Leong, 1996; Diamond et al., 2007; Greenfader \& Brouillette, 2013; Greenfader et al., 2015), concurring with the theoretical perspectives highlighted earlier in the paper. As selfefficacy theory suggests, teacher beliefs about drama integration likely shape their behaviors, thereby affecting children's learning outcomes (Bandura, 1997). It is worth noting, however, that given the small sample size which dictated the selection of the statistical analysis, it was not possible to examine other potentially important variables that could be at play. As such, various factors that could have contributed to the results in addition to the impact of drama, were not considered. Additionally, the learning context that drama integration creates could exert a direct influence on children's outcomes, which in turn aids children's construction of abstract, efficient linguistic and cognitive representations that transfer across social, language, and reading domains (Vygotsky, 1978).

The finding that the drama experience possibly engendered a change in preservice teachers' beliefs and attitudes toward teaching language and reading has important implications for future research and pedagogy. The results speak to the importance of including drama as a variable when developing assessments (formative and summative) and teaching tools focusing on drama integration, which have the potential of informing interventions aimed at professional development of preservice teachers. Interestingly, teachers' and parents' reports with respect to the drama experience were significantly associated, pointing to potentially converging evidence whereby both groups (teachers and parents) perceived drama as a positive experience that likely influences language and reading. However, given the study's small sample, the results must be interpreted with caution as they do not imply causation and only speak to the degree of association between the variables. Further, the use of a 4-point Likert scale has its limitations, including forcing the participants to choose an answer, and being less accurate compared to other scales. Future improvements, such as using a 7-point Likert scale with a large number of participants, are thus recommended.

The results of this study have implications for future research. As the findings 
suggest, engaging in drama training programs is associated with heightened drama integration in the classroom setting. It would be important to understand whether these skills remain consistent over time. This could be accomplished through conducting longitudinal investigations of drama integration in preschool settings. Furthermore, the current study focuses only on the beliefs and attitudes of preservice teachers (and parents) but does not measure the impact of their teaching practices on child outcomes directly. Directly assessing the different domains of language and reading of preschool children before and after drama workshops may provide a solid index of the effectiveness of drama integration in language and reading instruction.

In addition to informing research, this pilot study has implications for future pedagogy. The results demonstrate that teacher beliefs and attitudes about drama integration improved as a function of the drama workshop exposure. However, it is unclear whether and the degree to which teachers differed in their content knowledge of language and reading. Ensuring that the teachers have the necessary knowledge to teach language and reading is important for maximizing children's outcomes. Professional development should thus focus on training teachers in drama implementation with emphasis on evidence-based practice in the domains of language and reading (Banarjee et al., 2016; Roskos \& Christie, 2011) using a developmental approach to address the diversity of the language and reading profiles of preschool children.

\section{Conflicts of Interest}

The authors declare no conflicts of interest regarding the publication of this paper.

\section{References}

Alber, S., \& Foil, C. (2003). Drama Activities That Promote and Extend Your Students' Vocabulary Proficiency. Intervention in School \& Clinic, 39, 22-29. https://doi.org/10.1177/10534512030390010301

Anderson, A. et al. (2019). Dramatic Arts Integration Practices for Learning and Growth across PK-12 Development. The Journal of the Arts and Special Education, 1, 64-104.

Banarjee, R. et al. (2016). Supporting Sociodramatic Play in Preschools to Promote Language and Literacy Skills of English Language Learners. Early Childhood Education Journal, 44, 299-305. https://doi.org/10.1007/s10643-015-0715-4

Bandura, A. (1997). Self-Efficacy: The Exercise of Control. Freeman.

Bodrova, E., \& Leong, D. (1996). Tools of the Mind: The Vygotskian Approach to Early Childhood Education. Merrill.

Cawthon, S., Dawson, K., \& Ihom, S. (2011). Activating Student Engagement through Drama-Based Instruction. Journal for Learning through the Arts, 7, 1-28. https://doi.org/10.1007/s10643-015-0715-4

Diamond, A., \& Lee, K. (2011). Interventions Shown to Aid Executive Function Development in Children 4-12 Years Old. Science, 333, 959-964.

https://doi.org/10.1126/science.1204529

Diamond, A., Burnett, S., Thomas, J., \& Munro, S. (2007). Preschool Program Improves Cog- 
nitive Control. Science, 318, 1387-1388. https://doi.org/10.1126/science.1151148

Golinkoff, R., Hirsh-Pasek, K., \& Singer, D. (2006). Play = Learning: A Challenge for Parents and Educators. In D. Singer, R. Golinkoff, \& K. Hirsh-Pasek (Eds.), Play-Learning: How Play Motivates and Enhances Children's Cognitive and Social-Emotional Growth (pp. 3-12) . Oxford University Press.

https://doi.org/10.1093/acprof:oso/9780195304381.003.0001

Greenfader, C., \& Brouilette, L. (2013). Boosting Language Skills of English Learners through Dramatization and Movement. The Reading Teacher, 67, 171-180. https://doi.org/10.1002/TRTR.1192

Greenfader, C., Brouillette, L., \& Farkas, G. (2015). Effect of Performing Arts Program on the Oral Language Skills of Young English Learners. Reading Research Quarterly, 50, 185203. https://doi.org/10.1002/rrq.90

Huss, M. et al. (2011). Music, Rhythm, Rise Time Perception and Developmental Dyslexia: Perception of Musical Meter Predicts Reading and Phonology. Cortex: A Journal Devoted to the Study of the Nervous System and Behavior, 47, 674-689. https://doi.org/10.1016/j.cortex.2010.07.010

Mages, W. (2006). Drama and Imagination: A Cognitive Theory of Drama's Effect on Narrative Comprehension and Narrative Production. Research in Drama Education, 11, 329340. https://doi.org/10.1080/13569780600900750

Posner, M. et al. (2008). How Arts Training Influences Cognition. In C. Ashbury, \& B. Rich (Eds.), Learning, Arts, and the Brain: The Dana Consortium Report (pp. 1-10). The Dana Foundation.

Rieg, S., \& Paquette, K. (2009). Using Drama and Movement to Enhance English Language Learners' Literacy Development. Journal of Instructional Psychology, 36, 148-155.

Riggs, N., Greenberg, M., Kushe, C., \& Pentz, M. (2006). The Mediational Role of Neurocognition in the Behavioral Outcomes of a Social-Emotional Prevention Program in Elementary School Students: Effects of the Paths Curriculum. Prevention Science, 7, 91102. https://doi.org/10.1007/s11121-005-0022-1

Roskos, K., \& Christie, J. (2011). The Play-Literacy Nexus and the Importance of Evidence-Based Techniques in the Classroom. American Journal of Play, 4, 204-224.

Saraniero, P., Goldberg, M., \& Hall, B. (2014). “Unlocking My Creativity”: Teacher Learning in Arts Integration Professional Development. Journal for Learning through the Arts, 10, 24. https://doi.org/10.21977/D910119060

Sun, P. (2003). Using Drama and Theatre to Promote Literacy Development: Some Basic Classroom Applications. The Clearinghouse on Reading, English, and Communication Digest \#187.

Vygotsky, L. (1978). Mind in Society: The Development of Higher Mental Processes. Cambridge University Press.

Wandell, R. et al. (2008). Training in the Arts, Reading, and Brain Imaging. In C. Ashbury, \& B. Rich (Eds.), Learning, Arts, and the Brain: The Dana Consortium Report (pp. 5159). The Dana Foundation. 